\title{
Systematic review and meta-analysis: the effectiveness and safety of acupuncture in the treatment of herpes zoster
}

\author{
Tao Qi", Hua Lan", Chao Zhong, Ruwen Zhang, Huamei Zhang, Fang Zhu, Bing Ji \\ Pain Management, Hospital of Chengdu University of Traditional Chinese Medicine, Chengdu, China \\ Contributions: (I) Conception and design: T Qi, H Lan, F Zhu, B Ji; (II) Administrative support: C Zhong, R Zhang; (III) Provision of study materials \\ or patients: T Qi, H Lan, C Zhong, R Zhang, H Zhang; (IV) Collection and assembly of data: All authors; (V) Data analysis and interpretation: T \\ Qi, H Zhang, F Zhu, B Ji; (VI) Manuscript writing: All authors; (VII) Final approval of manuscript: All authors. \\ \#These authors contributed equally to this work. \\ Correspondence to: Fang Zhu; Bing Ji. Pain Management, Hospital of Chengdu University of Traditional Chinese Medicine, No. 39 Shierqiao Road, \\ Chengdu 610072, China. Email: emily20210707@163.com; jb_juninhot@163.com.
}

\begin{abstract}
Background: The treatment of herpes zoster (HZ) by the traditional Chinese medicine of acupuncture is attracting attention. However, there is still a controversy about the effectiveness and safety of acupuncture treatment of $\mathrm{HZ}$.

Methods: Articles on randomized controlled trials examining acupuncture and Western medicine treatments of HZ published since the establishment of the PubMed, Embase, Medline, and Chinese Biomedical Literature (CBM) databases to March 2021 were electronically retrieved. The Cochrane System Evaluation Manual was used for the data analysis with Review Manager 5.3 software, and the Cochrane Handbook version 5.3 systematic review writing manual was adopted to evaluate the risk of bias.
\end{abstract}

Results: In total, 11 articles, comprising 1,156 patients (585 in the experimental group and 571 in the control group) were included in the meta-analysis, and the results showed that the treatments used in the experimental and control groups were significant differences of total treatment efficiency [odds ratio $(\mathrm{OR})=6.76$; $95 \%$ confidence interval $(\mathrm{CI}): 3.46$ to $13.21 ; \mathrm{P}<0.05]$ in terms of the incidence of posterior neuralgia $(\mathrm{OR}=0.07 ; 95 \% \mathrm{CI}: 0.02$ to $0.21 ; \mathrm{P}<0.05)$, pain-relief time [mean difference $(\mathrm{MD})=-2.17 ; 95 \%$ CI: -2.90 to $-1.44 ; \mathrm{P}<0.05$ ], shingles time $(\mathrm{MD}=-1.61 ; 95 \% \mathrm{CI}:-2.84$ to $-0.38 ; \mathrm{P}<0.05)$, and scabbing time $(\mathrm{MD}=-1.62 ; 95 \% \mathrm{CI}:-2.64$ to $-0.61 ; \mathrm{P}<0.05)$, and patients' visual analogue scale (VAS) pain scores improved [standard MD (SMD) $=0.87 ; 95 \% \mathrm{CI}: 0.01$ to $1.73 ; \mathrm{P}=0.05$ ] was no significant difference.

Discussions: Compared to Western medicine treatments, acupuncture had a better effect on HZ, reduced the posterior neuralgia rate of patients, and shortened the course of treatment, but had no obvious effect on the relief of pain.

Keywords: Herpes zoster (HZ); acupuncture treatment; mate analysis; clinical efficacy

Submitted Jan 06, 2022. Accepted for publication Feb 16, 2022.

doi: 10.21037/apm-22-109

View this article at: https://dx.doi.org/10.21037/apm-22-109

\section{Introduction}

Herpes zoster (HZ) is a common skin disease caused by the reactivation of the varicella-HZ (VZV) virus, and is characterized by banded clusters of erythema blisters on the body, accompanied by severe neuralgia that seriously affects the patient's daily life (1). The VZV virus may reactivate due to age, stress, or decreased immunity, and spread along the sensory nerves to the skin, causing unique precursory pain followed by a rash. HZ can occur at any age, but is most common in elderly people (2). It is estimated that about $1 / 3$ of the population will develop HZ during their lifetime (3). The incidence of $\mathrm{HZ}$ and $\mathrm{HZ}$-associated complications increase with age $(4,5)$. HZ may cause post-HZ neuralgia 
(i.e., postherpetic neuralgia), which is the most common complication, and $10 \%$ of patients experience pain for more than a month, or even for years, which often leads to anxiety, insomnia and other problems that affect the normal life of patients (6,7). In Western medicine, $\mathrm{HZ}$ is mainly treated by antiviral and nutritional nerve drugs, Its treatment effect is poor (8). Over-the-counter or prescription painkillers are used when the pain is serious, but the side effects of some of the drugs are often difficult to ignore, and can include nausea, vomiting, and liver function damage $(9,10)$.

Studies have shown that the treatment effects of acupuncture and moxibustion on $\mathrm{HZ}$ are certain, result in only minimal pain, have a quick effect, are acceptable to patients, and are widely used in clinical practice. Acupuncture treatment $\mathrm{HZ}$ can be adjusted to local qi and blood, dispersing silt and clearing away heat, shorten the course of disease, dredge meridians and blood, rapidly blocking further damage to nerve, having obvious analgesic effect and can reduce neuralgia (11). There is some evidence that acupuncture may be beneficial in the treatment of neurological pain (12). Additionally, acupuncture is known to be a safe treatment with few adverse reactions (13). The curative effect of acupuncture in the treatment of this disease is certain. Acupuncture can be administered in many ways (e.g., via electric needle, fire needle, warm moxibustion, plum needle, acupuncture cupping, surrounding thorn, and acupuncture injection), but the acupoints and methods used are different. Notably, fire needle, no needle, puncture, and other methods have a remarkable treatment effect on $\mathrm{HZ}$, and can effectively relieve pain and promote $\mathrm{HZ}$ scabbing. However, very few studies have been conducted on acupuncture treatment in $\mathrm{HZ}$ patients, and the results of those studies have been controversial. Thus, there is a lack of extensive clinical research on this topic. This meta-analysis included randomized controlled clinical trials examining the use of acupuncture and Western medicine in the treatment $\mathrm{HZ}$ to compare the effectiveness of the two methods, the incidence of posterior neuralgia, visual analogue scale (VAS) pain scores before and after treatment, and pain-relief time, etc. We present the following article in accordance with the PRISMA reporting checklist (available at https://apm. amegroups.com/article/view/10.21037/apm-22-109/rc).

\section{Methods}

\section{Strategy for article retrieval}

The Embase, PubMed, Medline, and Cochrane Library databases were searched from January 1980 to March 2021 using the following search terms: "Acupuncture", "Herpes zoster", "treatment", "ischemic", "cerebrovascular", "herpes", "Pharmacoacupuncture", and "Randomized controlled trial". The terms were optimally combined to retrieve the most relevant articles. The search words had to appear in the scope of the title, keywords, or abstract. Some references in the included articles were also traced, and the full texts of the articles were manually searched and included in this study. After the retrieval, qualified randomized controlled trials were selected according to the inclusion and exclusion criteria for the meta-analysis.

\section{Inclusion and exclusion criteria}

To be eligible for inclusion in the study, the articles had to meet the following inclusion criteria: (I) be about clinical research; (II) include subjects who had been diagnosed with HZ; and (III) include an experimental group that received acupuncture therapy or acupuncture therapy combined with drug therapy, and a control group that received drug therapy.

Articles were excluded from the study if they met any of the following exclusion criteria: (I) was a literature review; (II) included animal subjects; (III) included repeated data; (IV) included acupuncture therapy combined with other treatments; (V) examined HZ combined with other diseases; and/or (VI) the full text of the article could not be obtained, or the data documents were incomplete.

\section{Article screening and data extraction}

The two researchers separately screened the articles according to the above-mentioned inclusion and exclusion criteria, and discussed any differences in opinions. If they could not reach a joint decision, a third researcher was asked to decide. The following data were extracted: the first author, publication year, basic data of research subjects, number of cases in experimental and control groups, treatment plan, and outcome indicators.

\section{Literature bias risk and methodological quality evaluation}

The quality evaluation was carried out according to the "bias risk assessment" recommended by Cochrane System Review Manual (version 5.3). In the evaluation, the following six questions were considered: how was the randomization generated? Was the assignment process biased? Did the researchers use blind methods in the study? Are the results 


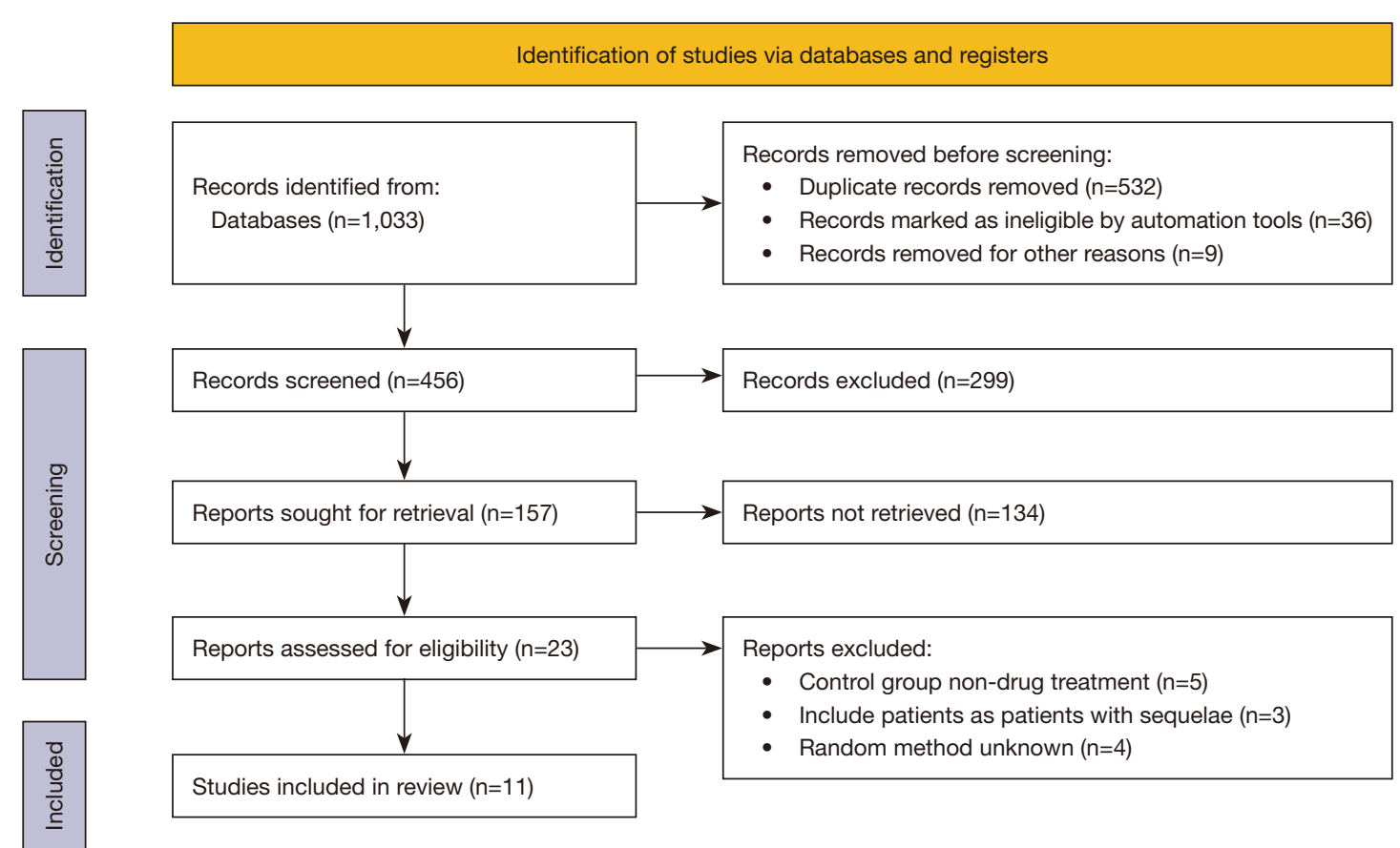

Figure 1 Flow chart of the article retrieval process.

and data complete? Were the study results selectively reported? Were there any other biases?

\section{Statistical analysis}

The Review Manager 5.3 software provided by the Cochrane Collaboration was used for the statistical analysis. Binclassification variables were needed to calculate the odds ratio (OR) or risk ratio (RR), and continuity variables were needed to calculate the mean difference (MD), standard MD (SMD), and 95\% confidence interval (CI), and express the results. A $\mathrm{P}$ value $<0.05$ was considered statistically significant. The heterogeneity of the articles was quantitatively evaluated using $\mathrm{I}^{2}$. An $\mathrm{I}^{2}<50 \%$ indicated no significant heterogeneity, and a fixed-effects model was used. An $\mathrm{I}^{2}>50 \%$ indicated significant heterogeneity, and a stochastic-effects model was used. Funnel maps were drawn for the analysis of the publication bias of the included articles, and the symmetry of the funnel maps was evaluated to see if the sample was concentrated around the center line.

\section{Results}

\section{Article retrieval}

Based on the Cochrane system retrieval strategy, 157 documents were retrieved, duplicate documents were then removed, and the title, abstract and full text were carefully read. Ultimately, 11 articles were included in this study (14-24). There were 1,156 patients, including 585 patients in the experimental group and 571 patients in the control group. Figure 1 shows the literature retrieval and screening flow. Table 1 sets out the basic data of the included articles.

\section{The literature quality evaluation}

The results of the quality evaluation of the 11 articles are shown in Figures 2,3. Notably, none of the 11 articles included in this study used random-sequence generation (indicating selection bias) or allocation concealment (indicating selection bias). Li's research included incomplete outcome data (indicating a high risk of attrition bias) (20). Liu's research included incomplete outcome data and selective reporting (indicating a high risk of reporting bias) (18). Additionally, the other studies had low or unknown risks.

\section{Total treatment efficiency}

Of the 11 articles, 8 reported on total treatment efficiency. The differences between the acupuncture and control treatments in terms of total efficiency are shown in Figure 4. 


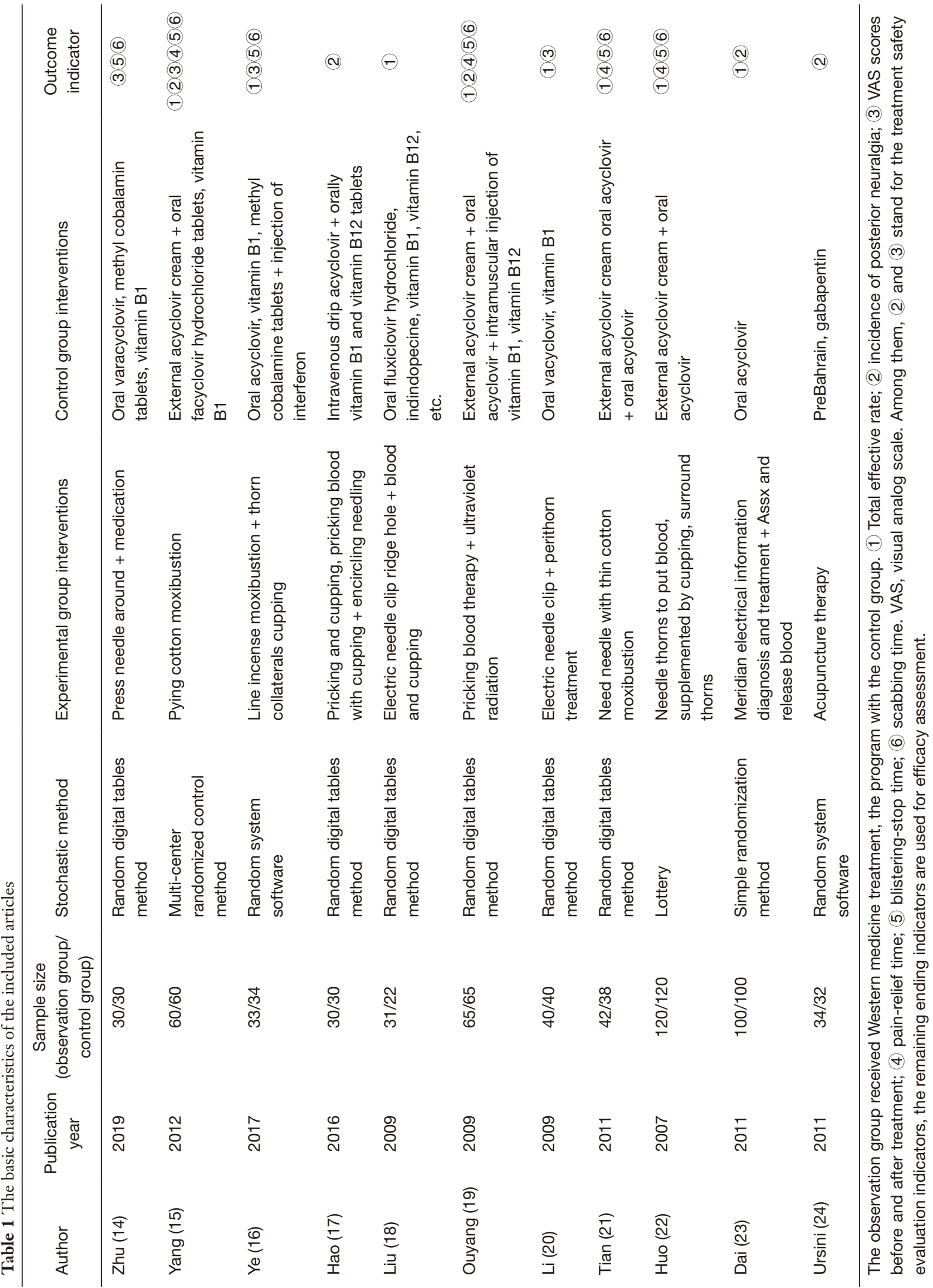




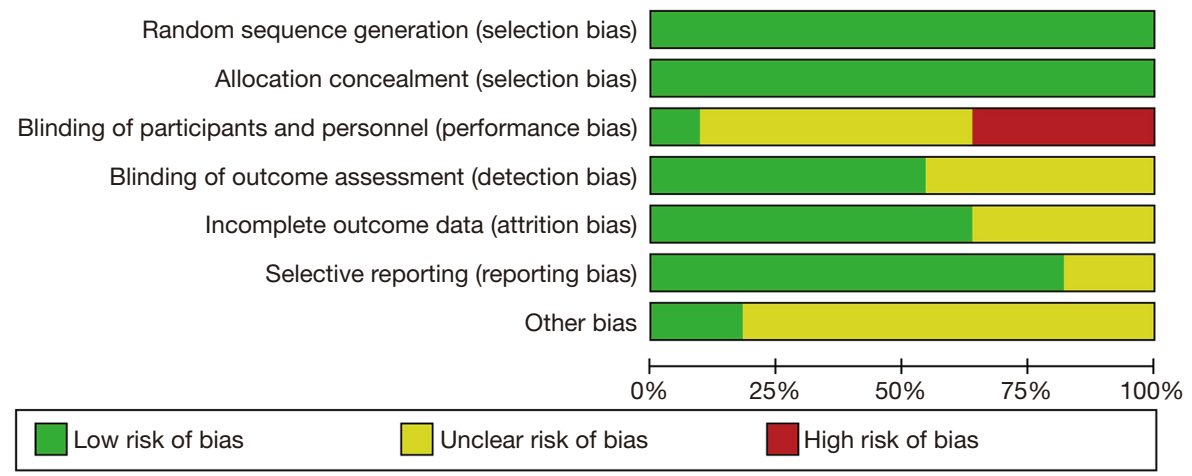

Figure 2 Assessment of the risk of bias of the included articles.

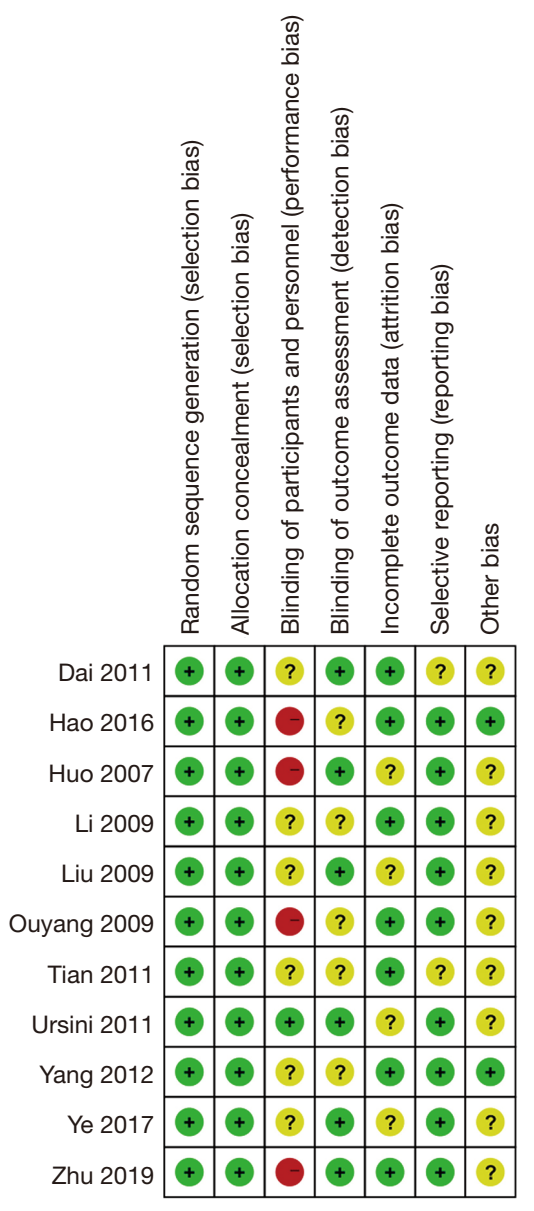

Figure 3 Multiple studies showed multiple risk biases.

The heterogeneity test $\left(\mathrm{I}^{2}=50 \% ; \mathrm{P}=0.05\right)$ indicated heterogeneity between the studies, and thus the randomeffects model was used. The effect value of the OR was 6.76 (95\% CI: 3.46 to 13.21). The transverse line fell on the right side of the invalid vertical line. The statistical test results were $Z=5.59$ and $P<0.00001$, indicating that the experimental treatment was significantly more efficient than the control treatment $(\mathrm{P}<0.05)$.

\section{Rate of posterior legacy neuralgia}

A total of 3 articles reported on the occurrence of posterior neuralgia in patients. The differences between the acupuncture and control groups were compared, and the results are shown in Figure 5. Based on the heterogeneity test $\left(I^{2}=43 \% ; P=0.18\right)$, there was no heterogeneity between the studies, and thus the fixed-effects model was used. The effect value of the OR was 0.07 (95\% CI: 0.02 to 0.21 ). The transverse line fell on the left side of the invalid vertical line. The statistical test results were $\mathrm{Z}=4.76$ and $\mathrm{P}<0.00001$, indicating that the incidence rate of the experimental group was significantly lower than that of the control group $(\mathrm{P}<0.05)$.

\section{VAS pain score before and after treatment}

A total of 6 articles evaluated the VAS scores before and after treatment, but only 4 articles stated the standardized average difference of the improved VAS score before and after treatment; the other 2 only stated the average score number and standard difference before and after treatment, and thus were excluded from the comparison. The comparison results are shown in Figure 6. The results were $\mathrm{I}^{2}=92 \%$ and $\mathrm{P}<0.00001$; thus, a random-effects model was used. The SMD was 0.87 (95\% CI: 0.01 to 1.73 ). The statistical test results showed $\mathrm{P}=0.05$, and were not statistically significant in experimental group and control group. 


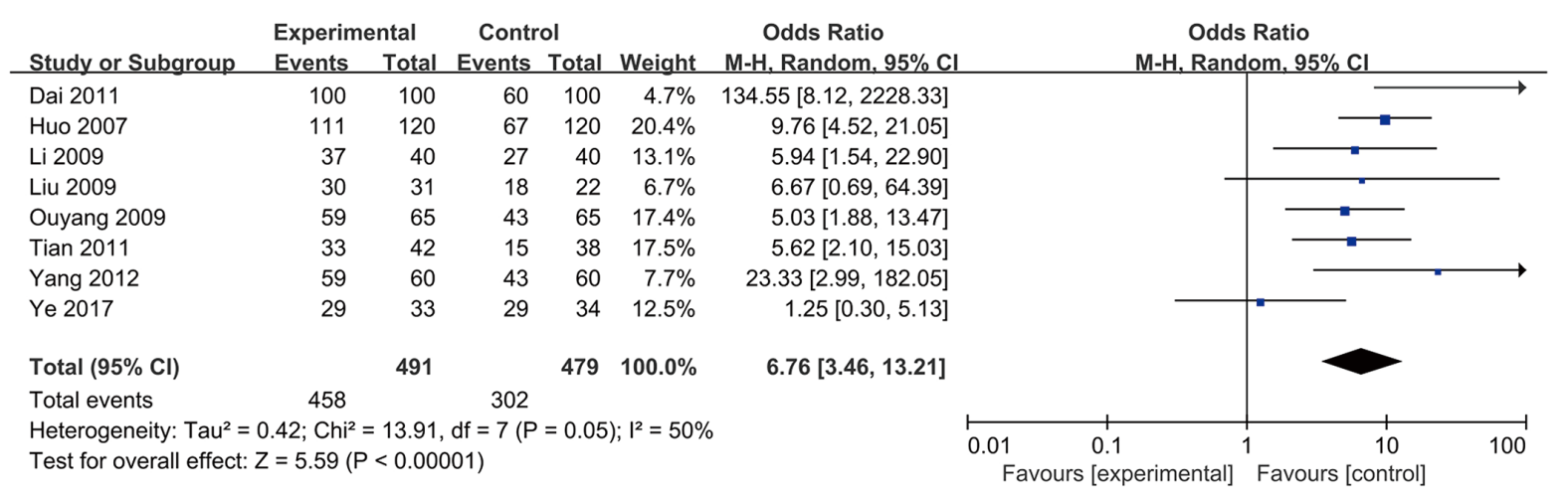

Figure 4 Forest map comparing total treatment efficiency. CI, confidence interval.

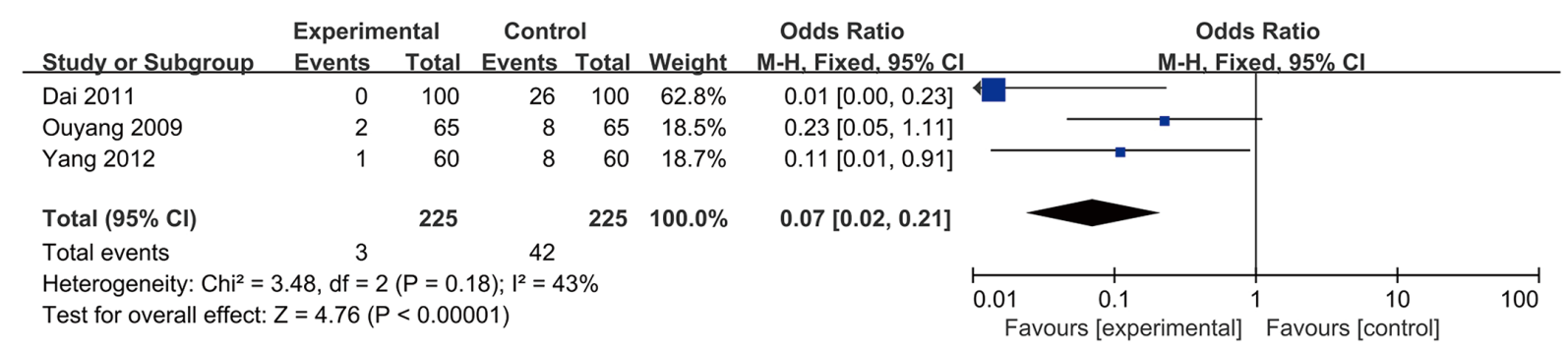

Figure 5 Forest map comparing the incidence of posterior neuralgia. CI, confidence interval.

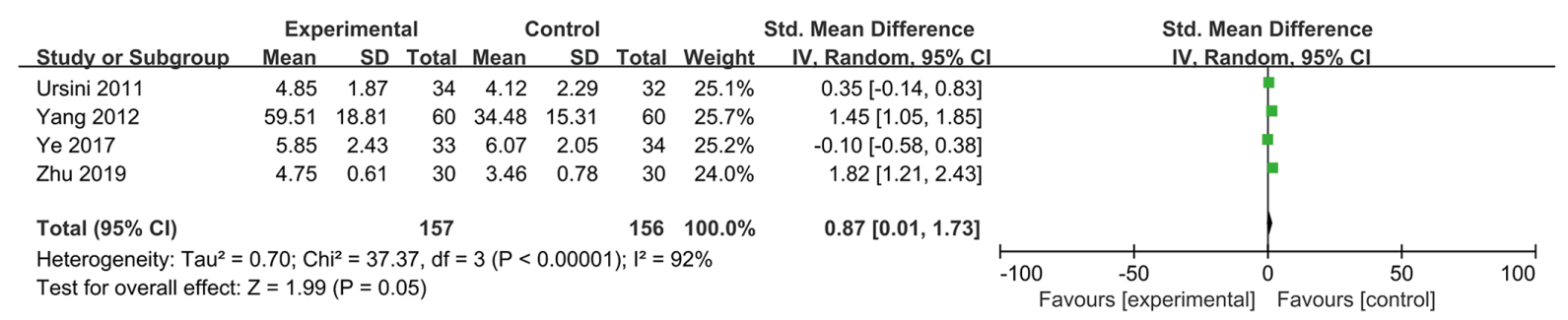

Figure 6 Forest map comparing VAS scores. VAS, visual analog scale; CI, confidence interval.

\section{Pain-relief time}

Pain-relief time was reported in 4 articles. The comparison results are shown in Figure 7. The heterogeneity test results $\left(\mathrm{I}^{2}=72 \% ; \mathrm{P}=0.01\right)$ indicated heterogeneity differences among the studies, and thus the stochastic-effects model was used. The results showed that the effect value of the MD was -2.17 (95\% CI: -2.90 to -1.44 ). The transverse line fell on the left side of the invalid vertical line. The statistical test results were $\mathrm{Z}=5.85$ and $\mathrm{P}<0.00001$, indicating that the pain-relief time was significantly shorter in the experimental group than the control group significant $(\mathrm{P}<0.05)$.

\section{Shingles time}

In total, 6 articles reported on the blistering-stop time of patients. The comparison results are shown in Figure 8. The heterogeneity test results $\left(\mathrm{I}^{2}=96 \% ; \mathrm{P}<0.00001\right)$ indicated heterogeneity between the studies, and random-effects model was used. The results showed that the effect value of the MD was -1.61 (95\% CI: -2.84 to -0.38 ). The transverse line fell on the left side of the invalid vertical line. The 


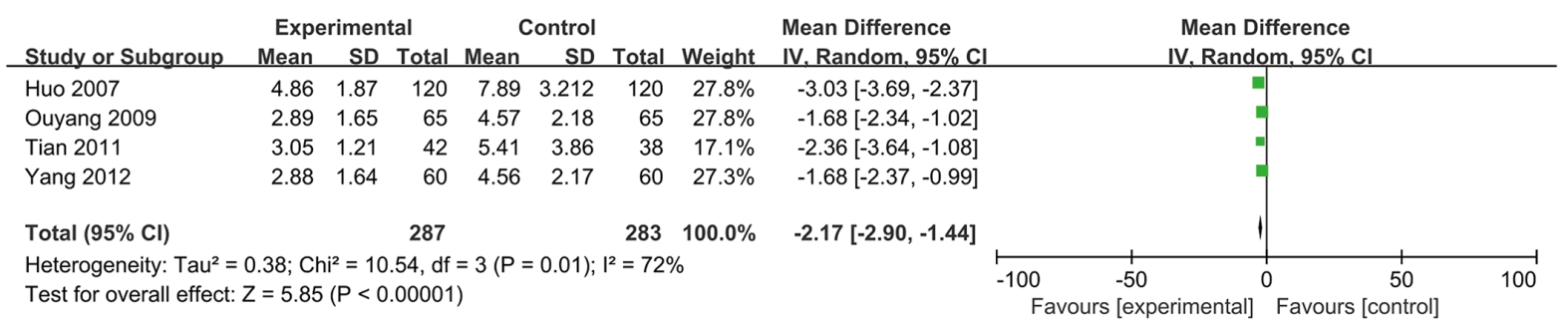

Figure 7 Forest map comparing pain-relief time. CI, confidence interval.

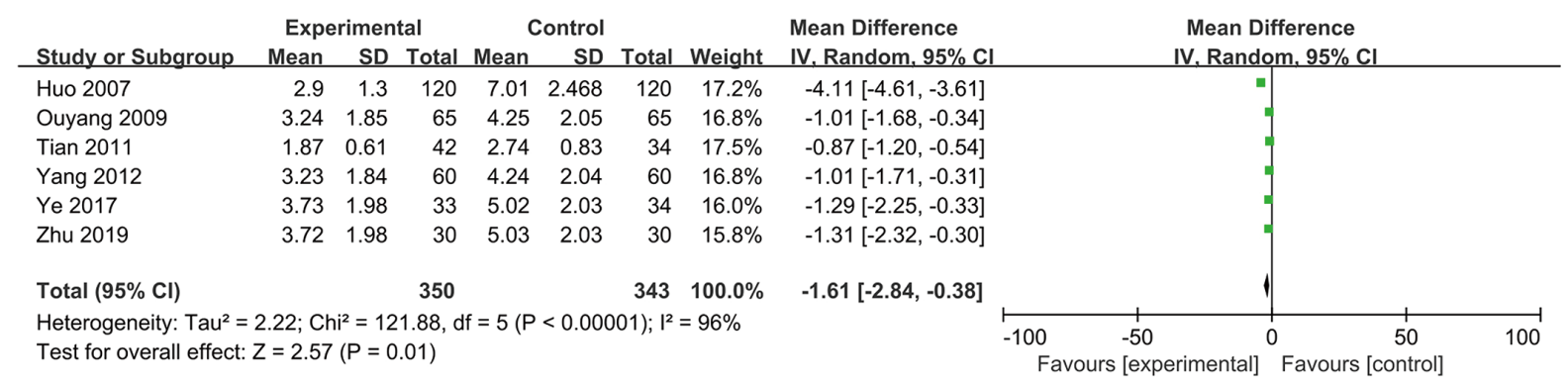

Figure 8 Forest map comparing blister-stopping time. CI, confidence interval.

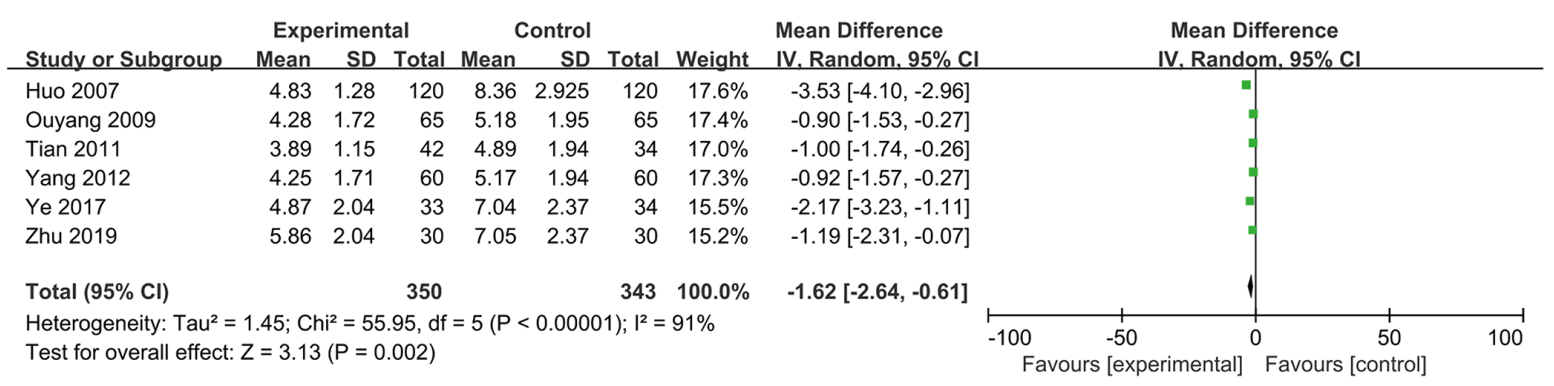

Figure 9 Forest map comparing scabbing time. CI, confidence interval.

results were $\mathrm{Z}=2.57$ and $\mathrm{P}=0.01$, indicating that the time was significantly shorter in the experimental group than the control group $(\mathrm{P}<0.05)$.

\section{Scabbing time}

A total of 6 documents reported on patients' scabbing time. The comparison results are shown in Figure 9. The heterogeneity test $\left(\mathrm{I}^{2}=91 \% ; \mathrm{P}<0.00001\right)$ indicated that there was heterogeneity between the studies, and randomeffects model was used. The results showed that the effect value of the MD was -1.62 (95\% CI: -2.64 to -0.61$)$. The transverse line fell on the left side of the invalid vertical line.
The statistical results were $Z=3.13$ and $P=0.002$, indicating that the scabbing time was significantly shorter in the experimental group than the control group $(\mathrm{P}<0.05)$.

\section{Analysis of literature publication bias}

An inverted funnel plot of the total efficiency of acupuncture in treating $\mathrm{HZ}$ and the improvement in VAS pain scores was produced to determine whether the articles had any publication bias. As Figure 10 shows, the total efficient graphic was asymmetrical, and almost all of the included studies fell within the inverted funnel plots. Only few studies did not fall into the inverted funnel plot. The possible 


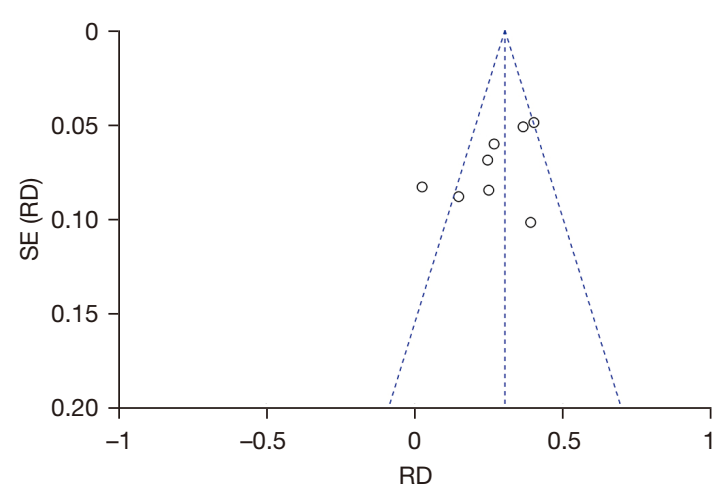

Figure 10 Total efficient publication bias funnel diagram. SE, standard error; RD, risk difference.

reasons were few literatures included in the meta-analysis and the heterogeneity between the articles. The funnel graph shape exhibits a symmetrical blade leakage, so incorporate research does not present literature publication bias.

\section{Discussion}

$\mathrm{HZ}$ is a common disease in elderly people, and occurs as age increases and immunity drops. The activation of the VZV can cause skin blisters, acute attacks, and pain. If it is not treated in time, it will cause chronic refractory neuralgia. Self-limiting herpes caused by VZV infection is characterized by local burning, pain, intense neuralgia, skin damage, and scabs. The earlier pain relief is provided, the less patients suffer. Drugs can effectively treat HZ, but it is not good to improve neuralgia. A large proportion of patients (18-41\%) experience severe or very severe pain, which usually persists after the rash has healed (25-27). The acute and chronic pain of post-HZ neuralgia may seriously affect patients' quality of life, carry high medical costs, and interfere with patients' physical, emotional and social functions (28).

Western medicine treatments of $\mathrm{HZ}$ focus on antiinflammation, infection prevention, shortening the course of the disease, and symptomatic treatment, and generally use antiviral drugs, B vitamins, corticosteroid hormones, transfer factors and interferons. Presently, antiviral drugs are considered an important step in the treatment of HZ, and the timely application of effective antiviral drugs, such as valaciclovir, acyclovir, and famciclovir, can prevent the destruction of the nerve, control acute symptoms, and prevent the occurrence of posterior neuralgia. However, such drugs have high medical cost and certain side effects.
Clinically, $10-15 \%$ of patients treated with antiviral drugs still experience severe neuralgia after the complete healing of skin lesions, and the incidence of post- $\mathrm{HZ}$ neuralgia has been reported to be as high as $50-85 \%$ (29).

Acupuncture has unique advantages and good efficacy, and offers a variety of clinical treatment options. Acupuncture may play an analgesic role by reducing central and peripheral sensitization, inhibiting glial activity, and regulating pain-related cell signaling pathways and the expression of receptors. Acupuncture has great advantages in the treatment of primary menstrual pain, cancer pain, nerve pain, and other pain diseases (30).

We conducted a meta-analysis of 11 studies, comprising 1,156 patients (585 in the experimental group and 571 in the control group). The studies examined the total efficiency, posterior pain rate, pain time, blistering time, scabbing time, and VAS pain score. The results showed that acupuncture and moxibustion treatments have obvious advantages in terms of both their efficiency, and in reducing the incidence of posterior neuralgia. Additionally, acupuncture treatment also quickly reduces the pain of patients and shortens the course of the treatment.

The following limitations may explain the biases found in this study. First, only 11 studies were included in the meta-analysis. Second, no unified indicators were used to assess the effect of acupuncture on HZ, and most of the results varied in the articles. Third, as acupuncture and moxibustion are external treatment methods, it was difficult to achieve the application of the blind method, which could have led to a bias in the results. Fourth, there are many specific methods of acupuncture. The literature included in this article is acupuncture, but the specific method has distinctiveness. Due to the constraint limitations of the article, it is impossible to discuss the acupuncture method of the literature. Fifth, the treatment times differed, which may have caused bias. Sixth, only 1 of the included article was published in English, and 1 in Italian, and the rest were published in Chinese, which may lead to language and regional biases. Finally, 1 of the experimental groups used acupuncture combined with Western medicine, but the other groups only used a simple acupuncture treatment, which may have led to bias in the results.

\section{Conclusions}

To systematically assess the effectiveness of acupuncture compared to Western medicine in the treatment of $\mathrm{HZ}$, 11 articles on randomized clinical trials were included 
in this meta-analysis. The results showed that the total efficiency of acupuncture treatment was significantly higher in the experimental group than the control group, and the incidence of neuralgia post treatment, the pain-relief time, blistering time, and the scabbing time were lower in the experimental group than the control group. Thus, acupuncture had a good effect on HZ, quickly reduced patient pain, shortened the course of the treatment, and reduce the incidence of posterior neuralgia. In relation to the VAS score, there was no difference between acupuncture and moxibustion and the degree of pain.

In summary, acupuncture has significant advantages in terms of its total efficiency and in the treatment of posterior neuralgia. Patients' pain is quickly reduced after acupuncture treatment. To address the limitations of this study, a set of standard evaluation criteria should be set, and the standard system should be designed according to the requirements of clinical randomized control trials, and multi-center large sample-size studies should be conducted to increase the accuracy and reliability of the results.

\section{Acknowledgments}

Funding: None.

\section{Footnote}

Reporting Checklist: The authors have completed the PRISMA reporting checklist. Available at https://apm. amegroups.com/article/view/10.21037/apm-22-109/rc

Conflicts of Interest: All authors have completed the ICMJE uniform disclosure form (available at https://apm. amegroups.com/article/view/10.21037/apm-22-109/coif). The authors have no conflicts of interest to declare.

Ethical Statement: The authors are accountable for all aspects of the work, including ensuring that any questions related to the accuracy or integrity of any part of the work have been appropriately investigated and resolved.

Open Access Statement: This is an Open Access article distributed in accordance with the Creative Commons Attribution-NonCommercial-NoDerivs 4.0 International License (CC BY-NC-ND 4.0), which permits the noncommercial replication and distribution of the article with the strict proviso that no changes or edits are made and the original work is properly cited (including links to both the formal publication through the relevant DOI and the license). See: https://creativecommons.org/licenses/by-nc-nd/4.0/.

\section{References}

1. Schmader K. Herpes Zoster. Ann Intern Med 2018;169:ITC19-31.

2. John AR, Canaday DH. Herpes Zoster in the Older Adult. Infect Dis Clin North Am 2017;31:811-26.

3. Shah RA, Limmer AL, Nwannunu CE, et al. Shingrix for Herpes Zoster: A Review Skin Therapy Lett 2019;24:5-7.

4. Dayan RR, Peleg R. Herpes zoster - typical and atypical presentations. Postgrad Med 2017;129:567-71.

5. Tran CT, Ducancelle A, Masson C, et al. Herpes zoster: Risk and prevention during immunomodulating therapy. Joint Bone Spine 2017;84:21-7.

6. Saguil A, Kane S, Mercado M, et al. Herpes Zoster and Postherpetic Neuralgia: Prevention and Management. Am Fam Physician 2017;96:656-63.

7. Mallick-Searle T, Snodgrass B, Brant JM. Postherpetic neuralgia: epidemiology, pathophysiology, and pain management pharmacology. J Multidiscip Healthc 2016;9:447-54.

8. Werner RN, Nikkels AF, Marinović B, et al. European consensus-based (S2k) Guideline on the Management of Herpes Zoster - guided by the European Dermatology Forum (EDF) in cooperation with the European Academy of Dermatology and Venereology (EADV), Part 2: Treatment. J Eur Acad Dermatol Venereol 2017;31:20-9.

9. Lewis DJ, Schlichte MJ, Dao H Jr. Atypical disseminated herpes zoster: management guidelines in immunocompromised patients. Cutis 2017;100:321;324;330.

10. Winthrop KL, Curtis JR, Lindsey S, et al. Herpes Zoster and Tofacitinib: Clinical Outcomes and the Risk of Concomitant Therapy. Arthritis Rheumatol 2017;69:1960-8.

11. Zhang N, Liu K, She Y, et al. Efficacy and safety of acupuncture and moxibustion for herpes zoster: A protocol for systematic review and network meta analysis. Medicine (Baltimore) 2020;99:e21905.

12. Yuan QL, Wang P, Liu L, et al. Acupuncture for musculoskeletal pain: A meta-analysis and meta-regression of sham-controlled randomized clinical trials. Sci Rep 2016;6:30675.

13. Paley CA, Johnson MI. Acupuncture for the Relief of Chronic Pain: A Synthesis of Systematic Reviews. Medicina (Kaunas) 2019;56:6. 
14. Zhu XX, Duan PB, Wu CZ. Efficacy of assisted treatment of thumb-tack acupuncture with surrounding needling method for herpes zoster of stagnated heat in liver meridian. Zhongguo Zhen Jiu 2019;39:149-53.

15. Yang JX, Xiang KW, Zhang YX. Treatment of herpes zoster with cotton sheet moxibustion: multicentral randomized controlled trial. Zhongguo Zhen Jiu 2012;32:417-21.

16. Ye G, Su M, Zhu D, et al. Effect of joss stick moxibustion combined with pricking and cupping for acute herpes zoster and its mechanism of analgesia. Zhongguo Zhen Jiu 2017;37:1289-93.

17. Hao P, Yang Y, Guan L. Effects of bloodletting pricking, cupping and surrounding acupuncture on inflammationrelated indices in peripheral and local blood in patients with acute herpes zoster. Zhongguo Zhen Jiu 2016;36:37-40.

18. Liu YN, Zhang HX, Huang GF, et al. Observation on therapeutic effect of electroacupuncture at Jiaji (EX-B 2) combined with blood-letting and cupping on herpes zoster. Zhongguo Zhen Jiu 2009;29:887-90.

19. Ouyang Q, Wei ZJ, Hou YL. Pricking blood therapy combined with ultraviolet irradiation for treatment of acute herpes zoster. Zhongguo Zhen Jiu 2009;29:285-8.

20. Li X, Zhang HX, Huang GF, et al. Observation on the therapeutic effect of electroacupuncture of Jiaji (EX-B 2) plus regional encircled needling for herpes zoster. Zhen $\mathrm{Ci}$ Yan Jiu 2009;34:125-7, 135.

21. Tian HY, Hu J, Yang JB. Comparison on therapeutic effect between surround needling plus thin cotton moxibustion and Western medicine for herpes zoster. Zhongguo Zhen Jiu 2011;31:219-22.

22. Huo HM, Yang XP. Observation on therapeutic effect of

Cite this article as: Qi T, Lan H, Zhong C, Zhang R, Zhang H, Zhu F, Ji B. Systematic review and meta-analysis: the effectiveness and safety of acupuncture in the treatment of herpes zoster. Ann Palliat Med 2022;11(2):756-765. doi: 10.21037/ apm-22-109 pricking blood therapy combined with acupuncture on herpes zoster. Zhongguo Zhen Jiu 2007;27:729-30.

23. Dai J, Yin AH, Zhou Y, et al. Herpes zoster treated with meridian-collateral electric information therapy combined with pricking and cupping. Zhongguo Zhen Jiu 2011;31:416-9.

24. Ursini T, Tontodonati M, Manzoli L, et al. Acupuncture for the treatment of severe acute pain in herpes zoster: results of a nested, open-label, randomized trial in the VZV Pain Study. BMC Complement Altern Med 2011;11:46.

25. Gross GE, Eisert L, Doerr HW, et al. S2k guidelines for the diagnosis and treatment of herpes zoster and postherpetic neuralgia. J Dtsch Dermatol Ges 2020;18:55-78.

26. Cunningham AL, Lal H, Kovac M, et al. Efficacy of the Herpes Zoster Subunit Vaccine in Adults 70 Years of Age or Older. N Engl J Med 2016;375:1019-32.

27. Ke DS, Hsu CY, Lin CL, et al. Herpes zoster in patients with sciatica. BMC Musculoskelet Disord 2020;21:813.

28. Tung YC, Tu HP, Wu MK, et al. Higher risk of herpes zoster in stroke patients. PLoS One 2020;15:e0228409.

29. Grupping K, Campora L, Douha M, et al. Immunogenicity and Safety of the HZ/su Adjuvanted Herpes Zoster Subunit Vaccine in Adults Previously Vaccinated With a Live Attenuated Herpes Zoster Vaccine. J Infect Dis 2017;216:1343-51.

30. Ifrim Chen F, Antochi AD, Barbilian AG. Acupuncture and the retrospect of its modern research. Rom J Morphol Embryol 2019;60:411-8.

(English Language Editor: L. Huleatt) 